\title{
Feedback on second language students' writing
}

\author{
Ken Hyland Institute of Education, University of London \\ k.hyland@ioe.ac.uk
}

Fiona Hyland University of Hong Kong

fhyland@hkucc.hku.hk

\begin{abstract}
Feedback is widely seen as crucial for encouraging and consolidating learning, and this significance has also been recognised by those working in the field of second language (L2) writing. Its importance is acknowledged in process-based classrooms, where it forms a key element of the students' growing control over composing skills, and by genre-oriented teachers employing scaffolded learning techniques. In fact, over the past twenty years, changes in writing pedagogy and research have transformed feedback practices, with teacher written comments often supplemented with peer feedback, writing workshops, conferences, and computer-delivered feedback. But while feedback is a central aspect of ESL/EFL writing programs across the world, the research literature has not been unequivocally positive about its role in writing development, and teachers often have a sense that they are not making use of its full potential. In this paper we examine recent research related to feedback on L2 students' writing, focusing on the role of feedback in writing instruction and discussing current issues relating to teacher written and oral feedback, collaborative peer feedback and computer-mediated feedback.
\end{abstract}

Feedback has long been regarded as essential for the development of second language (L2) writing skills, both for its potential for learning and for student motivation. In process-based, learner-centred classrooms, for instance, it is seen as an important developmental tool moving learners through multiple drafts towards the capability for effective selfexpression. From an interactionist perspective it is regarded as an important means of establishing the significance of reader responses in shaping meanings (Probst 1989). In genre classrooms feedback is a key element of the scaffolding provided by the teacher to build learner confidence and the literacy resources to participate in target communities. In fact, over the past twenty years, changes in writing pedagogy and insights gained from research studies have transformed feedback practices, with teacher written comments now often combined with peer feedback, writing workshops, oral-conferences, or computer-delivered feedback. Summative feedback, focusing on writing as a product, has generally been replaced or supplemented by formative feedback which points forward to the student's future writing and the development of his or her writing processes.
But while feedback is a central aspect of $\mathrm{L} 2$ writing programs across the world, the research literature has not been unequivocally positive about its role in writing development, and teachers often have a sense that they are not making use of its full potential. Many questions relating to feedback remain unanswered or only partially addressed: Does it make a difference to students' writing? If so, in what areas? What is the best way of delivering feedback? Can error correction and form focused feedback have long term benefits on students' writing? Can technology play a greater part in delivering feedback? What role can peer feedback play in writing development? How far does culture play a part in student responses to feedback? How can teacher feedback enhance students' ability to independently reflect on their writing? What are the implications of feedback for teacher control and text

KEN HYLAND is Professor of Education and Head of the Centre for Academic and Professional Literacies at the Institute of Education, University of London. He has considerable experience teaching and researching first and second language writing and has published over one hundred articles and ten books on writing and applied linguistics. Recent titles are Teaching and researching writing (Longman, 2002), Second language writing (Cambridge University Press, 2003), Genre and second language writing (University of Michigan Press, 2004) and Metadiscourse (Continuum, 2005).

Professor Ken Hyland, School of Culture, Language and Communication, Institute of Education, University of London, 20 Bedford Way, London WC1H OAL, UK. k.hyland@ioe.ac.uk

FIONA HYLAND has a Ph.D. from Victoria University of Wellington, New Zealand, on the subject of feedback in second language writing and is a lecturer in the Faculty of Education at the University of Hong Kong, where she coordinates the ELT specialism of the Masters in Education programme. She has 25 years of experience teaching and researching in the areas of TESOL and teacher education, and has published a number of papers on the subject of feedback to ESL writers.

Dr Fiona Hyland, Faculty of Education, University of Hong Kong, Pok Fu Lam Road, Hong Kong.fhyland@, hkucc.hku.hk 
appropriation? This paper reviews recent research which addresses these questions by focusing on teacher written and oral feedback, peer conferencing and computer-mediated feedback. The volume of this research means that we are forced to focus on L2 learners of English, although the issues are common to studies of learners of other languages.

\section{Teacher written feedback}

Despite increasing emphasis on oral response and the use of peers as sources of feedback, teacher written response continues to play a central role in most L2 and foreign language (FL) writing classes. Many teachers feel they must write substantial comments on papers to provide a reader reaction to students' efforts, to help them improve as writers and to justify the grade they have been given (K. Hyland 2003).

Research in the 1980s and early 1990s, however, began to question the effectiveness of teacher feedback as a way of improving students' writing. Early research on native English speakers (L1) suggested that much written feedback was of poor quality and was frequently misunderstood by students, being vague, inconsistent and authoritarian, overly concerned with error and often functioning to appropriate, or take over, student texts by being too directive (e.g. Knoblauch \& Brannon 1981; Connors \& Lunsford 1993; see also Ferris (2003: chapter 1) for a review). While Zamel (1985) painted a similarly bleak picture in L2 contexts, it is important to note that feedback research was in its infancy at that time and ideas of best practice in both giving feedback and designing studies to describe it were fairly rudimentary. More recent empirical research suggests that feedback does lead to writing improvements and this section highlights this research.

\subsection{Responding to error}

A substantial amount of the research on teacher written feedback in L2 writing contexts has been concerned with error correction and whether this benefits students' writing development. Research in this area has sought to explore whether error correction is effective and what strategies and treatments teachers use for error correction, and to discover the effects correction has on students' immediate revisions and their longer term development as writers.

One line of argument, influenced by process theories, claims that feedback on error to L2 students is discouraging and generally fails to produce any improvements in their subsequent writing (Robb, Ross \& Shortreed 1986; Kepner 1991; Sheppard 1992; Polio, Fleck \& Leder 1998; Fazio 2001). In a well-known summary of this literature, Truscott (1996) saw very little benefit in this kind of feedback and argued strongly that it was the responsibility of teachers to change student attitudes regarding what they should expect from teacher response by adopting a 'correction-free approach' in their classrooms (Truscott 1996, 1999). Recently, he responded to Chandler's (2003) experimental study, which found that the accuracy of students' writing improved significantly over a semester when they corrected their errors after feedback than when they did not. Truscott (2004: 342) queried Chandler's findings and reiterated that error correction may not just be ineffective, but even harmful to students' fluency and their overall writing quality, arguing that the time spent dealing with errors in class is better spent on additional writing practice.

Teachers have been reluctant to follow this advice, however, as they are acutely aware that accuracy in writing is important to academic and professional audiences and that so-called 'L2 errors' often stigmatize writers (Horowitz 1986; Johns 1995; James 1998). They also feel that they should respond to the needs of students themselves, who see error-free work as very important. Research on student preferences has consistently found that students expect teachers to comment on their written errors and are frustrated if this does not happen (Cohen \& Cavalcanti 1990; Leki 1991; Hedgcock \& Lefkowitz 1994; Cumming 1995; Ferris 1995; F. Hyland 1998; Ferris \& Roberts 2001; Lee 2004).

In addition, it has been argued that the research on the lack of effectiveness of error feedback is not nearly as conclusive as Truscott claims (e.g. Polio 1997; Ferris 1999, 2002, 2003, 2004). Statements that teachers' error feedback is often incomplete, arbitrary and inaccurate, for instance (e.g. Zamel 1985; Connors \& Lunsford 1993), have simply not been consistently demonstrated empirically. Clearly, teacher variation is a crucial issue in both feedback and in the design of classroom research and little can be said on the basis of a few studies. Lee's (2004) finding that half of her sample of Hong Kong teachers corrected errors inaccurately, for example, was based on a de-contextualised teacher correction task, while Ferris' (2006) more naturalistic in situ study found teacher feedback to be overwhelmingly accurate. Further research into the linguistic knowledge and backgrounds of teachers whose first language is not English may go some way to help explain such variations in feedback practices.

In fact, it is difficult to draw clear conclusions and generalizations from the literature as a result of varied populations, treatments and research designs. As we shall discuss below, written feedback is more than marks on a page, yet research procedures often remove it from the real classrooms and teacherstudent relationships within which it occurs (see F. Hyland \& K. Hyland 2001; Goldstein 2005).

Moreover, while marking mechanical errors can be frustrating, the view that there is no direct connection between correction and learning is greatly overstated. Master (1995), for instance, found that corrective feedback was effective when combined 
with classroom discussions. Fathman \& Whalley (1990) found positive effects for rewriting from feedback on both grammar and content and Ferris (2006) discovered that about $80 \%$ of students in her L2 sample were able to successfully edit errors marked by teachers in a subsequent draft, with only $10 \%$ making incorrect changes. But demonstrating that a student can utilize teacher feedback to successfully edit from one draft of a paper to the next tells us little about the learner's successful acquisition of the linguistic features addressed by the feedback (Truscott 1996).

The few studies that have looked beyond the immediate corrections in a subsequent draft, however, have noted improvements in students' language accuracy (Polio et al. 1998; F. Hyland 2003; Chandler 2003). Ferris (2006), for instance, showed that students made statistically significant reductions in their total number of errors over a semester in five major grammar categories with a particular reduction in verb and lexical errors. These results underline the importance of general language proficiency and metalingusitic awareness in writing development and support Yates \& Kenkel's (2002) argument that both error correction and its effectiveness must be seen in the context of a student's evolving mastery of overall text construction.

It is also worth pointing out that many studies of feedback on error have ignored how language acquisition occurs, although the influence of feedback on the learner's long term writing development fits closely with the SLA research (Goldstein, p.c). SLA studies indicate that second language acquisition takes place gradually over time and that mistakes are an important part of the highly complex developmental process of acquiring the target language. In fact, there may be a U-shaped course of development (Ellis 1997) where learners are initially able to use the correct forms, only to regress later, before finally using them according to the target language norms (e.g. Doughty \& Long 2003). We cannot, in other words, expect that a target form will be acquired either immediately or permanently after it has been highlighted through feedback. Even though explicit feedback can play an important role in second language acquisition, it needs time and repetition before it can help learners to notice correct forms, compare these with their own interlanguage and test their hypotheses about the target language. Attempting to establish a direct relationship between corrective feedback and successful acquisition of a form is, therefore, over-simplistic and highly problematic (e.g. Carson 2001; Ferris 2003).

While feedback alone will not be responsible for improvement in language accuracy, it is likely to be one important factor. One key variable here is the type of error feedback that is given, and a number of researchers have compared direct feedback, where the teacher makes an explicit correction, with indirect forms where he or she simply indicates that an error has been made by means of an underline, circle, code, etc. The role of explicitness in student uptake, or response to feedback, is important as while indirect error feedback may encourage learner reflection and self-editing (Lalande 1982), lower proficiency students may be unable to identify and correct errors even when they have been marked for them (Ferris \& Hedgcock 2005).

Findings on feedback type have been conflicting, largely due to the widely varying student populations, types of writing and feedback practices examined and the diverse research designs employed. Lalande (1982), for instance, reported a reduction in student errors with indirect feedback and Robb et al. (1986) discovered minimal long-term gains in accuracy compared with direct feedback practices. In a textual study of over 5,000 teacher comments, Ferris (2006) found that students utilized direct feedback more consistently and effectively than indirect types, partly as it involves simply copying the teacher's suggestion into the next draft of their papers. However, less explicit forms of feedback also led to accurate revisions most of the time and this occurred whether underlined errors were coded or not. Ferris notes, however, that students' short-term ability to edit some types of errors which were directly marked by feedback did not always translate into longterm improvement, while indirect feedback seemed to help them develop more over time. While this may be a discouraging finding for many teachers looking for evidence that their students are becoming more proficient writers, the importance of immediate improvement of drafts cannot be underestimated.

Another issue is whether different types of errors 'respond' differently to error treatment. Ferris (1999) suggests that some errors, such as problems with verbs, subject-verb agreement, run-ons, fragments, noun endings, articles, pronouns, and possibly spelling, can be considered 'treatable', because they 'occur in a patterned, rule-governed way'. In contrast, errors such as word choice and word order are 'untreatable', in that 'there is no handbook or set of rules students can consult to avoid or fix those types of errors' (1999: 6). Teachers tend to mark 'treatable' errors indirectly and 'untreatable' errors directly (Ferris 2006) and this is probably because they believe that students are unable to self-correct untreatable errors marked indirectly (Ferris 2006). Moreover, while students seem to be able to improve their language accuracy through feedback on form if they are taught the rules governing directly 'treatable' errors (Ferris 1999), idiosyncratic errors are more amenable to indirect feedback techniques, such as locating the type of error and asking students to correct it themselves (Ferris \& Roberts 2001).

Overall, students appear to attend to teacher error corrections and in most cases use them to make accurate changes in their texts. This seems to facilitate student writing improvement both in the short term 
and over time, although it must be admitted that longitudinal studies rarely span more than one semester. Improvements seem to be more likely if feedback is related to instruction and if indirect feedback methods are used. This last point might relate to SLA research which suggests that students need to invest more effort in processing the input they receive and are forced to notice discrepancies in their own work and the correct pattern they are trying to employ (see Gass \& Selinker 2001; Mitchell \& Myles 2004).

\subsection{Teacher stances and feedback practices}

Another key area of investigation has been the stance teachers take towards students' texts and the relationship they build with their learners when giving feedback. It has long been recognised that teachers approach texts with a number of different purposes in mind and that these may change with different assignments, different students and different drafts (Bates, Lane \& Lange 1993). Thus commentary on a draft is likely to serve more immediate pedagogical goals than that given on a final product, for instance, and process approaches mandate that teachers should comment on ideas in earlier drafts and on grammar in later drafts (e.g. Zamel 1985). Several researchers have observed, however, that because meaning is only realised through language, the content-form distinction creates a false dichotomy (K. Hyland 2003; Ferris \& Hedgcock 2005), and research has shown that varying this recommended 'meaning before form' pattern seems to make little difference to the quality of final products (Ashwell 2000). Outside the language class, of course, feedback is less concerned with the development of writing proficiency and more with appraising how students have processed content: writing is merely a medium by which students are judged on what they know of specific subject knowledge.

Teachers, moreover, do not simply respond to grammar or content but have other purposes. Teachers adopt various commenting strategies which vary according to the type of essay assigned, the point of the semester in which feedback is given, and the proficiency of the student (Ferris 1997; Ferris et al. 1997). Ferris et al. (1997), for instance, distinguished eight broad functions of response in 1500 teacher comments, ranging from 'Asking for unknown information' to 'Giving information on ideas'. More simply, F. Hyland \& K. Hyland (2001) and K. Hyland \& F. Hyland (2006b) collected these purposes under the overarching functions of PRAISE, CRITICISM and SUgGESTIONS, where suggestion and criticism are opposite ends of a continuum ranging from a focus on what is done poorly to a plan of action for its improvement.

We should also note that written feedback is not PURELY informational, for although the commentary may facilitate writing development it will only be effective if it engages with the writer. One increasingly studied social factor of this kind has been the ways teachers seek to structure activities through a course to ensure that students are able to interpret and use their comments effectively. Several studies have shown that feedback is not simply disembodied reference to student texts but an interactive part of the whole context of learning, helping to create a productive interpersonal relationship between the teacher and individual students (F. Hyland 1998; Conrad \& Goldstein 1999; F. Hyland \& K. Hyland 2001). F. Hyland (1998, 2000a) and K. Hyland \& F. Hyland (2006b), for instance, observed a close relationship between written and oral feedback and instruction, finding that the points made through explicit teaching were picked up and reinforced by written feedback and then recycled in both peer and student-teacher oral interactions. One way of establishing this link has been to encourage students to revise papers based on feedback and incorporate both final versions and drafts in a portfolio (Song \& August 2002; Hamp-Lyons 2006). This allows teachers to observe students' development, improve their own practices by judging students' uptake of feedback, and create a closer relationship with learners.

In addition, by using mechanisms such as cover sheets (Leki 1990), questionnaires, or writer autobiographies (Goldstein 2004) teachers are able to reveal student feedback preferences to enhance the effectiveness of their commentary and the students' revisions. In a longitudinal study, K. Hyland \& F. Hyland (2006b) found that teachers did not simply mark a text but used information about the student to contextualise the writing being done, the strengths and weaknesses of the individual student, and his or her explicit requests for particular kinds of help. To assist them, the two teachers studied not only made considerable use of the data provided in the cover sheets that students submitted with each piece of writing, but also considered the personality and possible response of the individual student to specific feedback points. This vividly illustrates that teachers do not give feedback in a vacuum but create a context for their remarks, making use of what they know of the writer to create an interpersonal link and target feedback to their personality and needs.

Another aspect of the teacher-learner relationship now beginning to receive attention is how teachers select appropriate language and style in their feedback to construct the kinds of relationships which can facilitate a student's writing development (F. Hyland \& K. Hyland 2001; K. Hyland \& F. Hyland 2006b). Essentially, teachers have to weigh their choice of comments to accomplish informational, pedagogic, and interpersonal goals simultaneously while taking account of likely student reactions. Negative feedback may have a detrimental effect on writer confidence 


\section{Feedback on L2 students' writing}

while premature and gratuitous praise can confuse students and discourage revisions (F. Hyland \& $\mathrm{K}$. Hyland 2001). Teachers often praise frequently as a means of building students' confidence, but students expect to receive constructive criticism rather than simple platitudes (Ferris 1995; F. Hyland 1998).

Teachers also seek to mitigate the full force of their criticisms and suggestions by the use of hedges, question forms, and personal attribution and to be more reticent about criticising students' ideas than their language choices (F. Hyland \& K. Hyland 2001; K. Hyland \& F. Hyland 2006b). However, while mitigation may foster a cooperative pedagogical environment, its indirect approach also carries the very real danger that students may miss the point of the comment or misinterpret the feedback (F. Hyland 2001b; K. Hyland \& F. Hyland 2006b). The choice between promoting positive affect or confronting writing weaknesses may be decided by targeting some errors only and leaving others to later drafts or assignments, but this certainly presents a serious dilemma for writing teachers who have to rely mainly on their experience and knowledge of their students.

\subsection{Student views on teacher feedback}

Attempts have been made to find out more about students' perspectives on teacher response, mainly through questionnaire research. Surveys of students' feedback preferences generally indicate that ESL students greatly value teacher written feedback and consistently rate it more highly than alternative forms such as peer and oral feedback (Radecki \& Swales 1988; Leki 1991; Enginarlar 1993; Saito 1994; Ferris 1995; Zhang 1995). Although most surveys show that students want teacher feedback to highlight their grammatical errors, some indicate that they also want teachers to give them feedback on the content and ideas in their writing. (Hedgcock \& Lefkowitz 1994, 1996). Studies also suggest that students like to receive written feedback in combination with other sources, including conferences (Arndt 1993; Hedgcock \& Lefkowitz 1994) and are positive about receiving indirect feedback on errors, giving them clues rather than corrections since they recognize that it encourages them to be more active in their use of feedback (Arndt 1993; Saito 1994; F. Hyland 2001a).

While most research has focused on feedback given by EFL or ESL writing teachers at undergraduate or pre-university levels, recent research has focused on feedback to L2 graduate students, particularly by disciplinary faculty. Prior's $(1995,1998)$ studies, for instance, looked at feedback from peers and faculty on writing in graduate geography and sociology courses, showing how the writing tasks and the faculty's response were shaped by the experiences, activities and goals the participants brought to and created within the seminars. Riazi's (1997) study of four Iranian graduate students in education showed that the students viewed feedback as important for improving their understanding of their discipline, but also saw form-based comments as a way of developing their L2. It may be, however, that students receive fewer form-focused comments than they wish. Zhu's (2004) survey, for example, suggests that faculty saw themselves primarily as providers of content-based summative feedback and regarded formative feedback on writing as the job of writing instructors.

Leki (2006) has looked at feedback given by faculty to L2 graduate students in a US university, analysing the written comments made by disciplinary faculty on student assignments and interviewing students to investigate their opinions about the value of written feedback in their development of disciplinary literacy. Most students reported that they found the feedback very useful but many also said they would have liked even more, especially feedback helping them to identify problems and giving them information about academic and disciplinary expectations. They also wanted feedback on how native speakers would express the same ideas, suggesting that - like Riazi's students - they wanted their feedback to have a dual content/language focus. There is a need for more investigations to address questions on how L2 instructors and disciplinary faculty can work together more closely to meet students' needs.

\subsection{Impact of teacher written feedback on students' writing}

Although L2 students themselves are positive about teacher written feedback, its contribution to writing development is still unclear, both in terms of its immediate impact on revisions to drafts and of the longer term development of their writing skills. Studies suggest that students may ignore or misuse teacher commentary when revising drafts. Sometimes they misunderstand it (Ferris 1995; Conrad \& Goldstein 1999), or they understand the problems pointed out but are unable to come up with a suitable revision (Ferris 1997; Conrad \& Goldstein 1999), and sometimes this causes them to simply delete the offending text to avoid the issues raised (F. Hyland 1998).

There is also the issue of whether student revisions in response to feedback improve their writing. Research is not conclusive on this as it is difficult to claim a direct causal relationship between feedback and revision since both take place within a complex of contextual factors which can influence the extent and success of revision after feedback (Conrad \& Goldstein 1999; Goldstein 2006). Research into feedback, however, 'has largely been non-contextual and non-social, focused largely on texts and conducted within a linear model of teacher respond and student revise' (Goldstein 2001: 77). 
Much of the research on error correction reflects experimental or analytical research techniques that ignore classroom realities and the preferences of students (e.g. Frantzen 1995; Polio et al. 1998; Ferris \& Roberts 2001; Chandler 2003). Such approaches have their place, but they cannot capture the impact that wider classroom, institutional and personal contexts have on the ways feedback is given, understood and negotiated between participants. Sociocultural perspectives on learning therefore see knowledge and understanding not as things that can be handed down but as constructed through interactive processes (Riazi 1997; Murphy 2000; Goldstein 2006; Villamil \& de Guerrero 2006). Teachers respond to students in their comments as much as texts, and experienced teachers often tailor their feedback to suit each student, considering their backgrounds, needs and preferences as well as the relationship they have with them and the ongoing dialogue between them (Ferris et al. 1997; F. Hyland 1998, 2001b). It may be, in other words, that what is effective feedback for one student in one setting is less so in another.

Context is a combination of factors related to the institution and writing programme as well as those that teachers and students bring to the interaction (F. Hyland 1998, 2000a; K. Hyland \& F. Hyland 2006b). Goldstein (2004, 2005), for instance, suggests that contextual factors can include socio-political issues that influence teacher status and morale, available resources and class size, institutional attitudes towards L2 writers, exams, and program philosophies about feedback. Similarly, teacher factors such as attitudes towards particular students or the content of their texts, and student factors like reactions to teacher feedback and their investment in the course can have an impact on feedback and revision. These factors have not been systematically incorporated into most feedback research designs, however, and we know little about their potential impact on feedback and student revision.

Attempts have been made, however, to link aspects of teacher feedback with student revision. Ferris (1997), for instance, looked at 110 first and second drafts of papers by ESL tertiary students and found that three quarters of substantive teacher comments on the drafts were used by the students and they tended to improve student papers. Very few of the changes (less than 5\%) actually had a negative effect, but revisions based on comments in the question form were judged as having mixed effects. Longer and more detailed text specific comments were also found to result in more positive revisions.

Researchers have also tried to find out what kinds of comments are most effective. Ferris \& Hedgcock (2005) suggest text-specific commentary is most likely to encourage revision. They also make the point that marginal comments have more immediacy and make it easier for students to locate the source of a problem and revise appropriately whereas end comments can be more useful for writing development, since they summarize major problems. Marginal comments are also considered to be more motivating since they show the reader actively engaged with the writer's text (Goldstein 2004). Conrad \& Goldstein (1999) also question the importance often attributed to comment type in revision success. Their findings from three case studies suggest that choosing to phrase comments as questions, declaratives or imperatives had far less impact on the success of revisions than the type of problem identified in the feedback. Problems dealing with facts and details in the content were revised successfully about half the time, while those dealing with argumentation and analysis were revised successfully only $10 \%$ of time, a finding supported by Ferris (2001). Problems dealing with facts and details in the content were revised successfully about half the time, while those dealing with argumentation and analysis were revised successfully only $10 \%$ of time, a finding supported by Ferris (2001).

A final key issue of students' responses to teacher feedback is that of 'text appropriation', or the idea that ownership of writing can be 'stolen' from a writer by the teacher's comments. L1 writing researchers have suggested that writers might follow directive comments too closely and lose the opportunity to develop as writers by merely rewriting their texts to reflect their teachers' preoccupations (Knoblauch \& Brannon 1984). These concerns have been raised in ESL discussions of feedback but have been rigorously questioned by Reid who suggested that text appropriation was 'largely a mythical fear of ESL writing teachers' (1994: 275). She pointed out the danger of confusing helpful intervention with appropriation and urged ESL teachers to focus instead on their roles as 'cultural informants and as facilitators for creating the social discourse community in the ESL writing classroom' (p. 275).

Appropriation and the socio-political aspects of giving feedback do, however, continue to be debated in the literature. F. Hyland (2000a) describes episodes where teachers overrode student decisions on use of feedback, raising issues relating to not just to the ownership of writing but also to the ownership and control of the revision processes, supporting Hall's (1995) point that appropriation may involve both concepts of good and bad writing products and good and bad writing behaviour.

Recently, the concept of appropriation has been redefined with the suggestion that appropriation can go in two directions. Appropriation of teacher feedback can be an active strategy used by novice academic writers as they develop their own voices and their familiarity with different genres. Tardy (2006) illustrates the complexity of this in her description of Chatri, an engineering doctoral student, whose sense of agency and ownership of his writing developed as 
he gained confidence over particular genres in specific settings. When he approached less familiar genres, he was more likely to adopt the words and ideas of his supervisor and advisor, gradually becoming a more independent writer as his sense of his own expertise evolved. Tardy suggests that this situated and fluid view of appropriation is important for any future studies of feedback, as students in English for Academic Purposes (EAP) classrooms often hold more expertise in their subject-matter content than their writing teachers.

\section{Teacher conferencing and oral feedback}

While it is widely accepted that oral interaction has an important role to play in the planning, writing or revision stages of producing a text in L1 contexts (Bruffee 1984b), the scope and extent of its contribution are still unclear, especially for L 2 writers. For many learners oral feedback takes place in writing conferences where there is potential for meaning and interpretation to be constantly negotiated. Originating in L1 contexts, significant numbers of L2 students now participate in writing conferences. Powers \& Nelson (1995) conducted a survey of writing centres at graduate institutions across the USA and discovered that a very large percentage of requests for graduate student conferences at writing centres was coming from L2 students, even though most centres had not considered specific strategies for these learners. However, as Williams \& Severino (2004) point out in their recent summary of writing centre issues, empirical research on writing centres and their effectiveness is surprisingly thin, despite a Journal of Second Language Writing issue (13.3, 2004) devoted entirely to writing centre research.

\subsection{Effectiveness of oral feedback}

Much of the literature focuses on advice for effective writing centre practices and the ways that conferences may need to be adapted to the L2 context. For example, it has been argued that the standard nondirective 'hands-off' mode of tutoring in the L1 context is not appropriate and that a more directive role for L2 tutors in their role as cultural and language informants is required (Thonus 1999, 2001, 2003, 2004; Blau \& Hall 2002). Blau \& Hall (2002) suggest that it may sometimes be necessary to reverse the usual practice for writing discussions and start by focusing on accuracy and formal issues then work towards the development and organisation of content.

Some issues remain only partially answered, especially the effectiveness of oral feedback for improving students' writing. It has been pointed out that some L2 learners have cultural or social inhibitions about engaging informally with authority figures such as teachers, let alone questioning them, and this can result in students passively and unreflect- ively incorporating the teacher's suggestions into their work (Goldstein \& Conrad 1990). Goldstein \& Conrad found that only those students who negotiated meaning successfully in conferences were able to carry out extensive and better revisions to their writing. This finding was supported by Williams (2004) who found greater uptake of tutor advice in terms of revisions when tutor suggestions were explicit, when students actively participated and negotiated in the conferences, and when they wrote down their plans during their sessions with tutors. Williams noted that negotiation was important especially for higher level text-based revisions, although her study suggested that the majority of revisions linked to conferences were, in fact, surface level ones.

Patthey-Chavez \& Ferris (1997) examined four teachers' writing conferences with a weaker and a more able student and linked the topics discussed in the conferences to student revision of their drafts. They found that all eight students used the teachers' suggestions in their revisions, but the weaker students tended to follow advice far more closely. More able students were more assertive and confident and often used the teachers' suggestions as a starting point for their own changes. Patthey-Chavez \& Ferris suggest that with less able students there is more danger that conferences will involve appropriation rather than intervention. It may be worth noting that the findings of all these studies are based on small numbers of students and teachers, raising the question about the influence of other contextual factors and the impact of individual teachers' conferencing approaches.

\subsection{Interaction in writing conferences}

Other research has focused on analysing the nature of the interactions that take place in writing conferences to try to uncover the elements that make for a successful interaction. Some studies have explored the purposes and roles of the tutor's talk in conferences (Harris 1995), and others have examined the topics discussed in the sessions, suggesting that these mainly focus on sentence level grammatical problems (Aljaafreh \& Lantolf 1994; Cumming \& So 1996; Williams 2002).

More pertinently, several studies have focused specifically on the ways that meaning is negotiated in conferences (Williams 2002, 2004; Weissberg 2006) and the effects of these negotiations on students' revisions of their texts (Goldstein \& Conrad 1990; Aljaafreh \& Lantolf 1994). Another focus has been on power and control of the conference dialogue, including aspects such as the roles of the participants, the length of turns, who initiates topics and the relative percentages of the dialogue contributed by tutors and students (Powers 1993; Cumming \& So 1996; Weigle \& Nelson 2004) Comparisons have also been made of the interactions of tutors when conferencing with native and non-native tutees (Thonus 2004). These studies suggest that control 
of most L2 interactions remains firmly in the hands of the tutors, despite the collaborative ideals of the writing conference.

A key focus in many studies is the Vygotskian concept of SCAFFOLDING. This concept, also known as 'assisted performance' (Ohta 2001), 'negotiated interaction' (Long 1996), and 'guided participation' (Lave \& Wenger 1991), encompasses the ways that the feedback delivered through the dialogue between teacher and student can enable the student writer to develop both his or her text and writing abilities (Williams 2002). However, despite the wide use of this term in the literature, it still remains a rather abstract concept. In order to help tutors provide effective scaffolding, Aljaafreh \& Lantolf (1994) attempt to catalogue some of the characteristics of effective scaffolding in an L2 context. They suggest scaffolded help needs to be offered only when needed and removed as soon as the learner is able to function independently; graduated according to the learner's changing proficiency needs; and must be given in a dialogic conversation actively involving both teacher and student. Williams (2004) suggests that teachers can scaffold interaction and the learner's movement towards autonomy by marking critical features in the text, simplifying the task, and 'modelling' indirectly by eliciting an improved performance from the writer.

Weissberg (2006) attempts to make the concept of scaffolding more concrete by providing a detailed examination of the ways that oral scaffolding can work with L2 writers through a linguistic analysis of interactions during four one-on-one, tutor-student writing conferences. He operationalizes scaffolding as a set of 'observable discourse mechanisms' which can help tutors to improve the quality of their interventions. Using data from the conferences, he illustrates how a tutor creates verbal linkages to the L2 writer through lexical and phrasal repetition, questioning, phrase completion and extension, summary and paraphrase statements, and statements of personal affiliation. Such links are then used as a springboard to make instructional points. Weissberg however, cautions that although his data show a tutor addressing student needs through interaction, the impact of this scaffolding on student writing still remains to be determined.

\section{Peer feedback and self-evaluation}

Strong justification for the use of peer response is found in four theoretical stances: process writing, collaborative learning, Vygotskian learning theory and interactionist theories of L2 acquisition (Liu \& Hansen 2002). Peer response is seen as an important support for the drafting and redrafting of process approaches to writing (Zamel 1985; Mittan 1989). Collaborative learning theory (Bruffee 1984a) encourages students to 'pool' their resources and both complete tasks they could not do on their own, learning through dialogue and interaction with their peers (Hirvela 1999). Vygotskian approaches also underline the importance of social interaction with peers as Vygotsky's (1978) theoretical construct of the Zone of Proximal Development suggests that writing skills can emerge with the mediation and help of others.

While not directly driving interest in peer feedback, interactionist perspectives offer an important theoretical foundation for it by suggesting how opportunities to negotiate meaning through group work are a means of encouraging more effective acquisition of the language (Long \& Porter 1985). Effective peer response is a key element of helping novice writers to understand how readers see their work. Interactional modifications can assist acquisition by making input available and comprehensible while providing learners with important opportunities for practice, for testing hypotheses about language use against peers' responses, and for revision and writing in response to peer feedback. It is therefore not surprising that peer response remains a popular source of feedback in the L2 classroom and a continuing area for research.

\subsection{Effectiveness of peer response}

The research literature claims many positive effects for peer feedback in both L1 and L2 contexts. In particular, it is seen as a way of giving more control and autonomy to students since it involves them actively in the feedback process as opposed to a passive reliance on teachers' feedback to 'fix' up their writing (Mendoca \& Johnson 1994). Freedman \& Sperling (1985), Mittan (1989) and Caulk (1994) consider that peer response provides students with an audience for their writing which is more authentic than teacher response tends to be. It also enhances the ability of peer reviewers to evaluate their own work by providing a sense of audience and a checklist of evaluative questions to apply to their own writing (Stoddard \& MacArthur 1993; Cheng \& Warren 1996). Since student reviewers perceive that other students experience the same difficulties in writing that they do, peer feedback may also lead to a reduction in writer apprehension and help them to develop their autonomy and self-confidence as writers (Chaudron 1984; Curtis 2001; Cotterall \& Cohen 2003;). Oral interactions with peers during the writing process can also provide social and affective support (Guerrero \& Villamil 1994; F. Hyland 2000b).

However, in the past decade, research has reassessed the value of this type of response for ESL writers and the assumption that what works well in the first language classroom can be transferred wholesale to the L2 context. Studies have questioned L2 students' ability to offer useful feedback to each other and 
queried the extent to which students are prepared to use their peers' comments in their revisions. Mendoca \& Johnson's (1994) study, for example, suggested that students were very selective about using peer comments in their revisions. Connor \& Asenavage (1994), moreover, claimed that peer feedback made only a marginal difference to student writing, finding that only $5 \%$ of revisions could be directly linked to peer comments compared with 35\% related to teacher comments.

Two explanations have been given for this failure to use peer feedback. First, student preferences and their beliefs about the relative value of teacher and peer feedback may impact on their use of feedback. Nelson \& Carson's (1998) interviews with L2 university students found that students preferred teacher feedback and were much more likely to incorporate it in their revisions. In Zhang's (1995) study of eighty-one college freshmen, $75 \%$ preferred teacher feedback to all other forms. Students tend to trust their teachers rather than their peers, believing that the teacher is the expert whereas their peers might not be knowledgeable enough to diagnose their problems (Sengupta 1998). Tsui \& $\mathrm{Ng}$ (2000) found that Hong Kong secondary students viewed the teacher as a 'figure of authority that guaranteed quality' (p. 149) and were reluctant to trust their peers. Second, there are questions about the quality of peer feedback. Some researchers (Leki 1990; Nelson \& Murphy 1992, 1993; Lockhart \& Ng 1993; Mendoca \& Johnson 1994; F. Hyland 2000a) have found that students have problems detecting errors and providing quality feedback, sometimes resorting to formulaic comments on each others' writing, or they may give inappropriate and over-critical feedback (Amores 1997) or overfocus on surface errors (McGroarty \& Zhu 1997).

However, despite these issues, peer feedback is still popular and many teachers and course designers continue to incorporate it in their courses and to report positive experiences from students. Liu (1997), for instance, found students to be more positive about peer response after a semester's experience of such sessions. Students had reservations about trusting their peers' comments and about their peers' ability to comment on subject areas they did not specialise in, but felt they had benefited from peer response at the textual, cognitive and communicative levels. It has been suggested that part of the reason for some of the negative findings may be related to the framing of research questions. Jacobs et al. (1998) argue that studies which ask students to make a choice between teacher and peer feedback are misleading, because peer and teacher comments do not have to be mutually exclusive. Their questionnaire survey of 121 L2 undergraduates found that $93 \%$ of students wanted to have peer feedback when it was given in conjunction with teacher feedback, rather than instead of it, a finding supported by Tsui \& Ng (2000)'s study of secondary students' uses and attitudes to peer feedback in Hong Kong, which also stressed the complementary roles of the two feedback sources.

\subsection{Training for peer response}

One area of research has been to look at ways of improving both the quality of written peer feedback given and the quality of the peer interactions through training and preparation. Studies generally suggest that careful preparation and training are essential for successful peer response. Stanley (1992), for instance, found that a group of university ESL students trained in peer evaluation offered more feedback and couched it more tactfully than an untrained control group and that student writers were more likely to use the feedback in their revisions. Other researchers have also found that students who have been trained in peer response can provide useful feedback to their peers (Hedgcock \& Lefkowitz 1992; Berg 1999; Paulus 1999). One study by Zhu (1995) examined the effects of training in small groups and found that peer reviewers were not only able to give more feedback but were also able to negotiate in a more interactive manner than those just watching a video demonstration of how to give feedback.

Other studies have found that students who receive peer review training generate significantly more comments and more relevant and specific comments (Min 2005) and that training promotes more meaning-based suggestions resulting in higher quality revisions (Berg 1999). An additional point that should be made here is that training is also likely to benefit student reviewers themselves as they are then in a better position to view their own texts from a reader's perspective (F. Hyland 2003; Ferris 2004).

\subsection{Collaboration and interaction in peer response sessions}

Another strand of research has adopted a Vygotskian sociocultural framework to examine peer response interactions and their effects on students' writing. Donato (1994) and other L2 writing researchers have expanded the notion of scaffolding from the more traditional view of the expert helping the novice to move through the zone of proximal development (Vygotsky 1978) to include 'mutual' peer scaffolding, where help can go in both directions and both parties are helping to extend each other's writing competence (Ohta 1995; DiCamilla \& Antón 1997; Antón \& DiCamilla 1998; Lim \& Jacobs 2001). The idea that novice writers may actually benefit from acting as peer readers has not, however, been a major feature of the literature and this bi-directional 
tendency has tended to restrict our understanding of genuine collaboration and mutually beneficial interaction among peers. In addition, few studies have looked at the revisions peers make in response to such interactions so that the types of interactions which might lead to successful revisions remain empirically vague.

Some researchers have tried, however, to uncover the way scaffolded peer assistance works by analysing peer interactions, focusing on aspects such as the functions and focuses of the interactions, the stances taken by the reader and the group dynamics (Mangelsdorf \& Schlumberger 1992; Nelson \& Murphy 1992; Guerrero \& Villamil 1994; Mendoca \& Johnson 1994; Lockhart \& Ng 1995; Villamil \& Guerrero 1996; Guerrero \& Villamil 2000). Despite concerns about the dynamics of peer groups, some studies have suggested that these can be positive. For example, Guerrero \& Villamil (2000) analysed dyadic interactions in which the partners were revising a narrative text written by one of them. They found that almost $80 \%$ of interactions were collaborative, and noted that successful peer dyads showed a concern for not hurting each other's feelings. However, Villamil \& Guerrero (2006) observe that while collaborative interventions predominated in this sample, they were working with a culturally and linguistically homogeneous group of students and such camaraderie might not be repeated in all teaching contexts.

In fact, it has been acknowledged that peer responders working in their L2 may lack communication and pragmatic skills for successful interaction and because such students may come from different cultural groups with different expectations about interactions, this may also affect both the nature and success of the interactions.

There has been a great deal of discussion about the relationship between culture and feedback, especially in terms of peer feedback. Cross-cultural issues are seen as an especially important consideration when organising ESL peer response groups (Carson \& Nelson 1994, 1996; Nelson \& Carson 1995; Nelson 1997). According to Allaei \& Connor (1990:24), 'conflict, or at the very least, high levels of discomfort may occur in multi-cultural collaborative peer response groups' and several studies have explored this possibility. Nelson \& Murphy (1992, 1993), for instance, found that students from different cultures had different expectations about such elements as the roles of group members, the mechanics of the group and politeness strategies. Nelson \& Carson (1998) suggest that students from 'collectivist' cultural orientations such as China and Japan often focus on group consensus and seek to avoid threatening group cohesion by suggesting changes to peers' texts. Nelson \& Carson (2006) argue that linguistic and cultural homogeneity may be an important contributing factor in successful peer response group interaction, perhaps because it is easier to maintain face in a group with speakers of the same language and cultural backgrounds who will better understand the nuances of each other's messages, helping to maintain group harmony.

This use of the concept of culture as an explanatory factor in ESL interactions is a controversial one which has been criticized by postmodern and poststructuralist theorists as essentialist and reductionist, not allowing for individual variation. Atkinson (1999) and Clifford (1992) have suggested using the term 'identity' for culture to avoid accusations of stereotyping. This issue is debated in detail in Nelson \& Carson (2006) and is one with important implications for further research focusing on peer feedback.

\subsection{Self-evaluation}

Students can make their own revisions without feedback and improve their writing significantly. It is therefore important not to overlook the writers themselves as critical readers and reviewers of their own texts. Educational research also suggests that feedback is more effective when information is gathered from the subjects themselves as well as others (Brinko 1993). In fact, most writing teachers would acknowledge that the ultimate aim of any form of feedback should be to move students to a more independent role where they can critically evaluate their own writing and intervene to change their own processes and products where necessary.

To do this, students need to develop metacognitive skills. Beach \& Eaton (1984) have suggested a link between lack of substantive revision and a lack of the skills to critically self assess one's work in first language contexts. Researchers in L1 contexts argued that this might be partially the result of age and level of development, but there might also be a need for specific training or instruction in self-assessment techniques: for example, Bereiter \& Scardamalia's (1987) use of procedural facilitation techniques and cueing for a development of revision strategies. A problem with self-evaluation for many writers is the difficulty of reading one's own text with the critical detachment of an outside reader. It has been claimed that instruction can assist the development of this critical detachment and is therefore a valuable, if indirect, source of feedback.

It has, however, been pointed out that strategy instruction or prompt techniques to encourage selfassessment are often quite mechanical and may fail to take account of the students' own goals and the context in which they are working. Peck (1990) examined the effects of prompts on revisions to an interpretative essay, using a broadranging and open-ended prompt. He found that 
writers' revising behaviour varied not just because of differences in knowledge about revising and in writing competence, but because individual writers brought their own goals to the writing process and represented the task in different ways. Cumming \& So (1996) compared tutoring sessions for ESL students on their writing using conventional error correction and procedural facilitation prompts and found that in both cases the teachers and students focused primarily on local errors. It seems that strategy instruction techniques are limited in their ability to improve students' revising skills due to their tendency to reduce complex processes to a simplistic formula. Perhaps more promising for selfevaluation, and discussed in the next section below, are computer-assisted packages and prompts which the students can use as a resource for checking their own writing.

There are also promising developments in selfevaluation and reflection via portfolio writing and other reflective course designs. For example, Johns (2006) describes a project she used successfully: the I-Search Paper, which requires extensive student reflection after the completion of a research writing task. The I-Search was originally designed by Macrorie (1980) to encourage student reflection and develop writer autonomy and gives students many opportunities to reflect upon their research and writing processes. From her experiences using this project with mainly L2 students, Johns (2006) argues that the process of completing this process helped her students to develop motivation, confidence, self-reflection, and meta-awareness skills and, thus, encouraged writer autonomy.

\section{Computer-mediated feedback}

As technology develops and computer facilities become more widely available, the role of the computer in both delivering and mediating feedback has become more visible in practice and research. Partly driven by the rapid advance of educational technologies and partly by a marked increase in the provision of distance courses and on-line research supervision, students now often find themselves reading feedback on their electronically submitted essays which has been produced by an unseen tutor, by their peers, or by the computer itself. Nor is computer feedback restricted to distance students, as learners increasingly exchange texts and comments with each other and with teachers through computer networks in writing workshops. Precisely how computers are used, however, largely depends on the underlying assumptions that teachers hold about literacy and language learning (Warschauer 2002), and we must always bear in mind that computers are tools and not a single instructional method. In this section we examine these key areas of electronic feedback and the research which explores its diversity and effectiveness.

\section{1 Computer conferencing}

The most widely employed use of computers for language teaching is that provided by the connectivity of networked computers. This offers two broad options, either SYNCHRONOUS WRITING, where students communicate with each other or the tutor in real time via discussion software on Local Area Networks or internet chat sites; and ASYNCHRONOUS WRITING, where students communicate in a delayed way, such as via email. Educators teaching online have began to see that computer-mediated communication (CMC) brings significant changes to the social dimension of learning, and claims have been made that this can empower students and make writing classes more collaborative.

Warschauer, Turbee \& Roberts (1996), for instance, suggest that CMC allows students to take a more active and autonomous role when seeking feedback, since they can raise questions when they want to and take the initiative in discussions. Student conferencing is also said to make discussion more 'student centred', foster a sense of community, encourage a sense of group knowledge, and increase student participation, since there are more opportunities for student-student interaction with the teacher as facilitator (Plass \& Chun 1996; KahmiStein 2000; Warschauer 2002). Other researchers have highlighted the dialogic role of asynchronous CMC and its potential to scaffold understanding of disciplinary knowledge and disciplinary writing characteristics (Hewings \& Coffin 2006).

It is also the case that a network can make student writing more widely available and so provide an audience of peers beyond the instructor, helping to create a greater awareness of audience and communicative purpose (Ware 2004). This kind of networked communication is said to motivate less proficient students (Warschauer 2002; Greenfield 2003) and provide a non-threatening environment for students to practice their literacy skills and receive peer feedback on their work (Colomb \& Simutis 1996). Finally, some researchers argue that it can lead to better writing products and more focused and better quality peer feedback (Sullivan \& Pratt 1996; Braine 1997). Tuzi (2004), for instance, found that e-feedback helped L2 writers focus on larger chunks of writing and work on macro-revisions.

For teachers, the use of networked computers assists the efficient exchange of student drafts (Palmquist 1993) and more easily facilitates the monitoring of peer feedback, as teachers can more easily switch between different screens than they can get around to a large number of small faceto-face groups (DiGiovanni \& Nagaswami 2001). One major advantage of electronic conferencing 
feedback is that comments are automatically stored for later retrieval, allowing instructors to print out the transcripts for in-class discussion. This kind of analysis of student writing can help build metacognitive awareness of particular linguistic, interactional and rhetorical features (Swaffar et al. 1998; Lamy \& Goodfellow 1999; Sengupta 2001). Teachers can use this database of transcripts to increase students' autonomy in correcting errors and in reflecting on their writing, and this can also have dramatic payoffs in self-feedback, and learner awareness of error (Yuan 2003). A down-side however, is that students may be overwhelmed by the commentary they receive on their work, making meaningful revisions more difficult.

Research has also addressed real-time synchronous communication via computer networks, especially the role of peer conferencing on writing (Heift \& Caws 2000). DiGiovanni \& Nagaswami (2001), for instance, found that students were more focused when providing feedback during real time electronic interaction than when engaging in traditional faceto-face peer revision groups. Similarly, in an experimental study, Schultz (2000) discovered that students made more SPECIFIC, LOCAL changes online and more GLOBAL changes in the face-to-face mode. This seemed to be because the online revisers were able to save and follow the detailed suggestions made in writing, while the face-to-face writers' global changes were facilitated by the more rapid back-andforth interaction. Students who received feedback in both modes made the most productive use of feedback.

There are, however, some concerns about CMC as a substitute for more traditional forms of feedback. Belcher (1999), for example, has cautioned that CMC can disadvantage the technologically challenged and Lindblom-Ylanne \& Pihlajamaki (2003) observed that their Finnish students felt threatened by sharing their drafts with peers in this way. van der Geest \& Remmers (1994) found the benefits of computermediated peer review offset by technical problems while Braine $(1997,2001)$ discovered that students in a face-to-face class produced better quality essays by the end of the semester than students in a LANmediated class. He attributes this to the fact that students seemed to have difficulties in following the rush of multiple discussion threads of online writing. This is a finding echoed by Liu \& Sadler (2003) who found that students using CMC, especially those using real-time communication in online chat rooms, made a greater number of comments, but these were more superficial and less helpful for revisions, perhaps due to the pressure to respond immediately. Face-toface interaction resulted in a more positive response with more focused feedback and more questions and interaction among peers.

Clearly, many of these difficulties are software and training related. With better designed software making navigation and communication easier, electronic peer and teacher review is likely to play a more important role in the feedback process, particularly if it is combined with traditional faceto-face activities rather than as a replacement for them. Of greatest importance, however, is that these technological tools are likely to offer their greatest benefits when they are integrated into the curriculum and closely matched to instructional purposes (K. Hyland 1993; Phinney \& Khouri 1993; Greenleaf 1994; Warschauer 1999).

Beyond LAN-mediated peer and teacher reviewing, the internet provides a context for L2 students to engage in personal communication and to receive feedback from native-speaking peers (Kern \& Warschauer 2000). Through various websites, students can find 'key pals', or one-toone email partners, in order to communicate in the target language with native language partners. By using language for real communication in these electronically mediated interactions, students appear to produce more output and report being more motivated to write (Barson, Frommer \& Schwartz 1993; Meagher \& Castaños 1996; Warschauer 1997). Tella (1992), for instance, found that students not only wrote in a wider range of genres and used a larger vocabulary using email when communicating with L1 English speakers, but that classroom instruction was no longer teacher-directed and so provided more opportunities for individualized, learner-centred workshops. More widely, these kinds of interaction not only offer feedback on writing but also on L2 development and intercultural communication skills themselves (e.g. Liu et al. 2002; O’Dowd 2003).

\subsection{Automated feedback}

Another area with a growing impact on feedback practices is the development of sophisticated software capable of scanning student texts and generating immediate evaluative comments on them. Different types of feedback are offered by such programmes, ranging from individual reports on grammatical errors, targeting ESL students (Liou 1994; Warden \& Chen 1995), to holistic assessments of content, organization, and mechanics (Burston 2001). Eventually such programmes may assist teachers with the burdens imposed by growing class sizes and increasing expectations for individualised support. In these circumstances, automated essay evaluation might be seen as a cost effective way of replacing or enhancing direct human input. For teachers they hold out the possibility of respite from the hours spent commenting on student papers, allowing them to focus on other aspects of their teaching, and for students they may provide more extensive feedback in a much shorter turn-around time.

At the moment, however, the main impetus for the development and use of these programmes comes from large international language testing 
Feedback on L2 students' writing

organizations which are increasingly delivering products such as IELTS and TOEFL electronically across the world. Their goal is to be able to accurately and economically rank content-restricted essays automatically (Valenti, Neri \& Cucchiarelli 2003), and as a result, much of the current research on automated feedback tends to focus on its efficiency in offering summative feedback on limited aspects of writing performance.

Among the best known of these automated feedback systems are the Criterion E-RATER developed by the Educational Testing Services (ETS) and MY Access! developed by Vantage Learning. The E-RATER (Burstein 2003; Burstein, Chodorow \& Leacock 2004), for example, scans a student text and provides a holistic score with real-time feedback on grammar, usage, style, organization and development. Other kinds of automated feedback programmes, such as the Respond module of the Daedalus Integrated Writing Suite (Daedalus 2005), provides a heuristic for selfevaluation. This steers students through an evaluative process using a series of modifiable prompts as learners revise their drafts, with questions appearing in the upper half of a window and students responding in the lower half while consulting their text in another window.

Such programmes are relatively new and their impact on the development of L2 writing has yet to be systematically evaluated. Generally, automated response programmes have been criticized for being unreliable (Krishnamurthy 2005) and realising poor pedagogic principles (Chapelle 2001), so whether the statistical techniques they use can provide useful feedback on L2 writing is an open question (Hearst 2000). We might also wonder whether such automated feedback systems will ever be able to deal with more than a few, very narrow and questionably useful genres. In fact, many developers of automated feedback software insist that computer-generated feedback should only be considered a supplement to, rather than a substitute for, classroom instruction (Burstein \& Marcu 2003; Burstein et al. 2004).

In particular, there is little research on the social, cognitive and communicative dimensions of automated feedback or on the potential dangers of ignoring meaning negotiation in real world contexts or the effects of isolated learning. Perhaps more seriously, while they go beyond the often misleading and prescriptive information provided by early grammar checkers, these programmes tend to treat writing as mastery of a set of sub-skills, laying particular emphasis on grammatical correctness. In the automated context, writing is not evaluated as real interaction designed to achieve different communicative purposes with different audiences but as a performance artefact of student mastery of grammar, usage, and organization. So while it remains unclear what specific advantages these new products will offer, the dangers of such systems emphasising formulaic writing which better lends itself to systematic codification cannot be overestimated (Ware \& Warshauer 2006).

\subsection{Corpora-based feedback}

The use of language corpora and concordancing offers one of the most exciting applications of new technologies to the writing class, providing teachers with evidence of language use not available from other sources and moving away from pre-programmed CALL to redefine the computer as a tool.

Electronic corpora are becoming increasingly important in L2 writing instruction as teaching becomes less a practice of imparting knowledge and more one of providing opportunities for learning. Essentially, a corpus is a collection of relevant texts which can be computer searched for particular words, phrases or grammatical patterns using concordancing software to reveal their frequency and regular patterns of use with other forms. Corpora offer exciting possibilities for innovative uses of feedback in two main ways. First, by making corpus evidence accessible during the writing process itself to increase learner autonomy and self-feedback on their work; and second, by offering teacher feedback which links electronically submitted writing directly to a concordance file.

Integrating concordancing software into the writing process can give students direct access to corpus information as they write. This offers L2 novice writers a cognitive support tool with which to check their evolving language hypotheses. There are a growing number of online resources that can be exploited to help students self-edit in this way, including search engines such as Google (Joyce \& Weil 2000). More targeted text-retrieval sites can help students clarify the strong selectional restrictions of specific words in more specific and relevant contexts. These include WordPilot 2000 (Milton 1999), CHeCK MY words (Milton 2006) and Word NEIGHBORS (Milton 2004) all of which create a macro in word processing programmes so that writers are able to call up a concordance for a word by double clicking while they are typing. This gives them frequency and contextual information about words and expressions when they need it.

More widely used are corpus-linked programmes which help teachers provide resource-assisted feedback. Encouraging students to submit their writing electronically allows teachers to hyperlink errors in an essay directly to a concordance file where students can examine the contexts and collocations of the words they have misused (Milton 1999; K. Hyland 2003). A sophisticated version of this is Milton's (2006) Mark my words, which allows teachers to insert customizable comments in any language in the student's electronic document and to link the comments to the online resources including corpus data. The program can identify 
word classes and lexical patterns and shortlist suggested comments when the teacher right-clicks the mouse, so minimizing the time needed to insert comments while guiding teachers who are unsure of grammatical terminology in selecting appropriate comments. There is some preliminary evidence that students are able to benefit from this kind of feedback. Todd (2001), for example, reports a study in Thailand where students were able to make inductive decisions about language use and to self-correct their common lexical errors after they had made small concordances of these items on the internet. Gaskell \& Cobb (2004) also report learner self-correction of grammatical errors after tutors pasted in links to an online concordance to facilitate feedback and reflection.

While the impact of these tools is an area for further investigation, they appear to offer considerable promise for supporting teacher feedback with authentic language data. By relieving students of the need to accept the teacher's editing of their words, teachers can relinquish some control and allow students to make their own decisions about revising their texts, based on both the feedback and the authentic data. This encourages a reflective, active response to a teacher's feedback which can be extremely useful for raising students' awareness of genre-specific conventions, developing independent learning skills, and improving writing products.

\section{Indications for future research}

While the research into feedback on L2 students' writing has increased dramatically in the last decade, it is clear that the questions posed at the beginning of this paper have not yet been completely answered. There are, for example, still uncertainties concerning the most effective ways of responding to different text features, the role of context, personal preference and interpersonal factors in giving and responding to feedback, and the best ways to employ peer and oral feedback. Nor are we a lot closer to understanding the long term effects of feedback on writing development. On the plus side, however, feedback studies have moved away from a narrow obsession with the effectiveness of error correction and the practice of peer feedback to embrace a new range of issues, so that we are now more aware of the potential of oral conferencing and computermediated feedback, of the importance of exploring student preferences and responses to feedback, and the role of wider social, institutional and interactional factors on feedback and its uptake. The research also points to some promising lines of future research.

One obvious direction for such research is towards more systematic and comprehensive descriptions of the contextual environments in which feedback is given and used. Contextual factors which are likely to repay further investigation include the relationship between classroom instruction and teachers' comments, the impact of various individual, social and cultural issues on both teacher commentary and student revision, and the role of local institutional constraints. These features also need to be considered together with more research designed to understand the longitudinal effects of teacher comments on student writing, focusing on questions such as what types of feedback lead to writing development over time and whether revisions to drafts show improvement in later writing situations.

Since the most important role of response is to help students to develop into independent writers who are able to critique and improve their own writing, another key area of research is the need for studies into the role of feedback in promoting autonomous writing skills. In particular, we believe that research into peer feedback and self-evaluation is likely to yield useful results in how response might lead to greater independence, while further work is also needed into what aspects students can revise without help from their teachers. Do some areas seem more accessible to self-assessment and, if so, which areas are these?

As we have seen, the research on oral feedback in writing is still quite limited and the effects of oral response on revision and longer-term writing improvement have not been fully investigated. Both teachers and students tend to be positive about the opportunities for detailed discussion that conferences offer, but conferences vary considerably in the extent to which they improve student writing, and the literature does not yet provide the kind of guidance that teachers need to be confident in their planning and interactions. More studies are required on students' perceptions of oral conferences, how they might best be prepared to make the most of them, and the effects of oral responses not just on immediate revisions, but on the longer term development of students as writers. Related to these issues, we also need research which tracks how, why and when writers respond favourably to oral and peer feedback over prolonged periods, particularly as writers' beliefs are likely to play an important part in this.

A final key area for research must be the potential of automated essay evaluation and computermediated feedback for improving student writing and developing their independent writing skills. We have little information on students' views of these programs or the effects of computergenerated response, so research examining students' perceptions, and use, of electronic feedback systems in naturalistic settings is needed. Since there are likely to be many developments in such software in coming years, this will be a prime area of research related to feedback as will further research on areas of computer feedback such as online social interaction and revision practices. Research is sure to continue in a range of areas related to computer feedback as technology changes our conceptions of both instruction and L2 literacy and as teachers continue 
to integrate technology into their writing classrooms. Most importantly however, future research into computer-mediated response, like all the forms of feedback we have discussed in this review, must as far as possible seek to integrate response, instruction, revision and writing development in its focus and the cultural, institutional and social dimensions of feedback in its design.

\section{References}

Aljaafreh, A. \& J. Lantolf (1994). Negative feedback as regulation and second language learning in the zone of proximal development. The Modern Language Journal 78.4, 465-483.

Allaei, S. \& U. Connor (1990). Exploring the dynamics of cross-cultural collaboration. The Writing Instructor 10.1, 1928.

Amores, M. (1997). A new perspective on peer editing. Foreign Language Annals 30.4, 513-523.

Antón, M. \& F. DiCamilla (1998). Socio-cognitive functions of L1 collaborative interactions in the L2 classroom. Canadian Modern Language Review 54.3, 314-342.

Arndt, V. (1993). Response to writing: Using feedback to inform the writing process. In M. Brook \& L. Walters (eds.), Teaching composition around the Pacific rim: Politics and pedagogy. Clevedon: Multilingual Matters, 90-116.

Ashwell, T. (2000). Patterns of teacher response to student writing in a multi-draft composition classroom: is content feedback followed by form feedback the best method? Journal of Second Language Writing 9.3, 227-257.

Atkinson, D. (1999). TESOL and culture. TESOL Quarterly 33.4, 625-654.

Barson, J., J. Frommer \& M. Schwartz (1993). Foreign language learning using e-mail in a task-oriented perspective: Interuniversity experiments in communication and collaboration. Journal of Science Education and Technology 4.2, 565-584.

Bates, L., J. Lane \& E. Lange (1993). Writing clearly: Responding to ESL composition. Boston: Heinle and Heinle.

Beach, R. \& S. Eaton (1984). Factors influencing self-assessing and revising by college freshmen. In $\mathrm{R}$. Beach \& $\mathrm{L}$. Bridwell (eds.), New directions in composition research. New York: Guilford Press, 149-170.

Belcher, D. (1999). Authentic interaction in a virtual classroom: Levelling the playing field in a graduate seminar. Computers and Composition 16.2, 253-267.

Belcher, D. \& G. Braine (eds.) (1995). Academic writing in a second language: Essays on research and pedagogy. Norwood, NJ: Ablex.

Bereiter, C. \& M. Scardamalia (1987). The psychology of written composition. Hillsdale, NJ: Lawrence Erlbaum.

Berg, E. (1999). The effects of trained peer response on ESL students' revision types and writing quality. Journal of Second Language Writing 8.3, 215-241.

Blau, S. \& J. Hall (2002). Guilt-free tutoring: Rethinking how we tutor non-native English speaking students. Writing Center Journal 23.1, 23-44.

Braine, G. (1997). Beyond word processing: Networked computers in ESL writing classes. Computers and Composition 14.1, 45-58.

Braine, G. (2001). A study of English as a foreign language (EFL) writers on a local-area network (LAN) and in traditional classes. Computers and Composition 18.3, 275292.

Brinko, K. (1993). The practice of giving feedback to improve teaching. Journal of Higher Education 64.5, 574-593.

Bruffee, K. (1984a). Collaborative learning and the 'conversation of mankind'. College English 46.7, 635-652.
Bruffee, K. (1984b). Peer tutoring and the conversation of mankind. In G. Olsen (ed.), Writing centers: Theory and administration. Urbana, IL: NCTE, 3-14.

Burstein, J. (2003). The e-rater scoring engine: Automated essay scoring with natural language processing. In Shermis \& Burstein (eds.), 113-122.

Burstein, J., M. Chodorow \& C. Leacock (2004). Automated essay evaluation: The Criterion online writing service. AI Magazine, 25.3, 27-36.

Burstein, J. \& D. Marcu (2003). Developing technology for automated evaluation of discourse structure in student essays. In Shermis \& Burstein (eds.), 209-230.

Burston, J. (2001). Computer-mediated feedback in composition correction. CALICO Journal 19.1, 37-50.

Carson, J. (2001). Second language writing and second language acquisition. In T. Silva \& P. Matsuda (eds.), On second language writing. Mahwah, NJ: Lawrence Erlbaum, 191-200.

Carson, J. \& G. Nelson (1994). Writing groups: Cross-cultural issues. Journal of Second Language Writing 3.1, 17-30.

Carson, J. \& G. Nelson (1996). Chinese students' perceptions of ESL peer response group interaction. Journal of Second Language Writing 5.1, 1-19.

Caulk, N. (1994). Comparing teacher and student responses to written work. TESOL Quarterly 28.1, 181-187.

Chandler, J. (2003). The efficacy of various kinds of error correction for improvement of the accuracy and fluency of L2 student writing. Journal of Second Language Writing 12.3, 267-296.

Chapelle, C. (2001). Computer applications in second language acquisition: Foundations for teaching, testing, and research. Cambridge: Cambridge University Press.

Chaudron, C. (1984). The effects of feedback on students' composition revisions. RELC Journal 15.2, 1-15.

Cheng, W. \& M. Warren (1996). Hong Kong students' attitudes toward peer assessment in English language courses. Asian Journal of English Language Teaching 6, 6175.

Clifford, J. (1992). Traveling cultures. In C. Grossberg, C. Nelson \& P. Triechler (eds.), Cultural studies. New York: Routledge, 96-116.

Cohen, A. \& M. Cavalcanti (1990). Feedback on compositions: Teacher and student verbal reports. In Kroll (ed.), 155-177.

Colomb, G. \& J. Simutis (1996). Visible conversation and academic inquiry: CMC in a culturally diverse classroom. In Herring (ed.), 203-224.

Connor, U. \& K. Asenavage (1994). Peer response groups in ESL writing classes: How much impact on revision? Journal of Second Language Writing 3.3, 257-276.

Connors, R. J. \& A. Lunsford (1993). Teachers' rhetorical comments on student papers. College Composition and Communication 44.2, 200-223.

Conrad, S. M. \& L. Goldstein (1999). Student revision after teacher written comments: Text, contexts and individuals. Journal of Second Language Writing 8.2, 147-180.

Cotterall, S. \& R. Cohen (2003). Scaffolding for second language writers: Producing an academic essay. ELT Journal $57.2,158-66$.

Cumming, A. (1995). Fostering writing expertise in ESL composition instruction: Modeling and evaluation. In Belcher \& Braine, (eds.), 375-397.

Cumming, A. \& S. So (1996). Tutoring second language text revision: Does the approach to instruction or the language of communication make a difference? Journal of Second Language Writing 5.3, 197-226.

Curtis, A. (2001). Hong Kong student teachers' responses to peer group process writing. Asian Journal of English Language Teaching 11, 129-143.

Daedalus (2005). Integrated Writing Environment [Computer software]. Austin, TX.: The Daedalus Group. 
DiCamilla, F. \& M. Antón (1997). Repetition in the collaborative discourse of L2 learners: A Vygotskian perspective. Canadian Modern Language Review 53.4, 609-633.

DiGiovanni, E. \& G. Nagaswami (2001). Online peer review: an alternative to face-to-face? ELT Journal 55.3, 263-272.

Donato, R. (1994). Collective scaffolding in second language learning. In J. Lantolf \& G. Appel (eds.), Vygotskian approaches to second language research. Norwood, NJ: Ablex, 33-56.

Doughty, C. \& M. Long (2003). The handbook of second language acquisition. Oxford: Blackwell.

Ellis, R. (1997). Second language acquisition. Oxford: Oxford University Press.

Enginarlar, H. (1993). Student response to teacher feedback in EFL writing. System 21.2, 193-204.

Fathman, A. \& E. Whalley (1990). Teacher response to student writing: focus on form versus content. In Kroll (ed.), 178-190.

Fazio, L. (2001). The effect of corrections and commentaries on the journal writing accuracy of minority- and majoritylanguage students. Journal of Second Language Writing 10.4, 235-249.

Ferris, D. (1995). Student reactions to teacher response in multiple-draft composition classrooms. TESOL Quarterly 29.1, 33-53.

Ferris, D. (1997). The influence of teacher commentary on student revision. TESOL Quarterly 31.2, 315-339.

Ferris, D. (1999). The case for grammar correction in L2 writing classes: A response to Truscott (1996). Journal of Second Language Writing 8.1, 1-10.

Ferris, D. (2001). Teaching writing for academic purposes. In J. Flowerdew \& M. Peacock (eds.), Research perspectives on English for academic purposes. Cambridge: Cambridge University Press, 298-314.

Ferris, D. (2002). Treatment of error in second language student writing. Ann Arbor, MI: The University of Michigan Press.

Ferris, D. (2003). Response to student writing. Mahwah, NJ: Lawrence Erlbaum.

Ferris, D. (2004). The 'grammar correction' debate in L2 writing: Where are we, and where do we go from here? (and what do we do in the meantime...?) Journal of Second Language Writing 13.1, 49-62.

Ferris, D. (2006). Does error feedback help student writers? New evidence on the short- and long-term effects of written error correction. In K. Hyland \& F. Hyland (eds.), 81-104.

Ferris, D. \& J. Hedgcock (2005). Teaching ESL composition: Purpose, process, and practice. Mahwah, NJ: Lawrence Erlbaum.

Ferris, D., S. Pezone, C. Tade \& S. Tinti (1997). Teacher commentary on student writing: Descriptions and implications. Journal of Second Language Writing 6.2, 155182.

Ferris, D. \& B. Roberts (2001). Error feedback in L2 writing classes: How explicit does it need to be? Journal of Second Language Writing 10.3, 161-84.

Frantzen, D. (1995). The effects of grammar supplementation on written accuracy in an intermediate Spanish content course. Modern Language Journal 79.3, 329-344.

Freedman, S. \& M. Sperling (1985). Written language acquisition: The role of response and the writing conference. In S. W. Freedman (ed.), The acquisition of written knowledge: Response and revision. Norwood, NJ: Ablex.106-130.

Gaskell, D. \& T. Cobb (2004). Can learners use concordance feedback for writing errors? System 32.3, 301-319.

Gass, S. \& L. Selinker (2001). Second language acquisition: an introductory course (2nd edn.). Mahwah, NJ: Lawrence Erlbaum.

Goldstein, L. (2001). For Kyla: What does the research say about responding to ESL writers. In T. Silva \& P. Matsuda, (eds.), On second language writing. Mahwah, NJ: Lawrence Erlbaum, 73-90.

Goldstein, L. (2004). Questions and answers about teacher written commentary and student revision: Teachers and students working together. Journal of Second Language Writing 13.1, 63-80.

Goldstein, L. (2005). Teacher written commentary in second language writing classrooms. Ann Arbor, MI: The University of Michigan Press.

Goldstein, L. (2006). In search of the individual: Feedback and revision in second language writing. In K. Hyland \& F. Hyland (eds.), 185-205.

Goldstein, L. \& S. Conrad (1990). Student input and negotiation of meaning in ESL writing conferences. TESOL Quarterly 24.3, 443-460.

Greenfield, R. (2003). Collaborative e-mail exchange for teaching secondary ESL: A case study in Hong Kong. Language Learning and Technology 7.1, 46-70.

Greenleaf, C. (1994). Technological indeterminacy: The role of classroom writing practices and pedagogy in shaping student use of the computer. Written Communication 11.1, 85-130.

Guerrero, M. de \& O. Villamil (1994). Social-cognitive dimensions of interaction in L2 peer revision. The Modern Language Journal 78.4, 484-496.

Guerrero, M. de \& O. Villamil (2000). Activating the ZPD: Mutual scaffolding in L2 peer revision. The Modern Language Journal 84.2, 51-68.

Hall, C. (1995). Comments on Joy Reid's 'Responding to ESL students' texts: The myths of appropriation'. There are myths and then there are myths. TESOL Quarterly 29.1, 159-163.

Hamp-Lyons, L. (2006). Feedback in portfolio based writing courses. In K. Hyland \& F. Hyland (eds.), 140-161.

Harris, M. (1995). Talking in the middle: Why writers need writing tutors. College English 57.1, 27-42.

Hearst, M. (2000). The debate on automated essay grading. Intelligence Systems 15.5, 22-37.

Hedgcock, J. \& N. Lefkowitz (1992). Collaborative oral/aural revision in foreign language writing instruction. Journal of Second Language Writing 1.3, 255-276.

Hedgcock, J. \& N. Lefkowitz (1994). Feedback on feedback: Assessing learner receptivity to teacher response in L2 composing. Journal of Second Language Writing 3.2, 141163

Hedgcock, J. \& N. Lefkowitz (1996). Some input on input: Two analyses of student response to expert feedback in L2 writing. The Modern Language Journal 80.3, 287-308.

Heift, T. \& C. Caws (2000). Peer feedback in synchronous writing environments: A case study in French. Educational Technology and Society 3.3, 208-214.

Herring S. (ed.) (1996). Computer-mediated communication: Linguistic, social, and cross-cultural perspectives. Amsterdam: John Benjamins.

Hewings, A. \& C. Coffin (2006). Formative interaction in electronic written exchanges: fostering feedback dialogues. In K. Hyland \& F. Hyland (eds.), 225-244.

Hirvela, A. (1999). Collaborative writing instruction and communities of readers and writers. TESOL Quarterly 8.2, $7-12$.

Horowitz, D. (1986). Process not product: Less than meets the eye. TESOL Quarterly 20.1, 141-144.

Hyland, F. (1998). The impact of teacher written feedback on individual writers. Journal of Second Language Writing $7.3,255-286$.

Hyland, F. (2000a). ESL writers and Feedback: Giving more autonomy to students. Language Teaching Research 4.1, 3354.

Hyland, F. (2000b). Teacher management of writing workshops: Two case studies. Canadian Modern Language Review 57.2, 272-294. 
Feedback on L2 students' writing

Hyland, F. (2001a). Providing effective support: investigating feedback to distance language learners. Open Learning 16.3, 233-247.

Hyland, F. (2001b). Dealing with plagiarism when giving feedback. English Language Teaching Journal 55.4, 375382 .

Hyland, F. (2003). Focusing on form: student engagement with teacher feedback. System 31.2, 217-230.

Hyland, F. \& K. Hyland (2001). Sugaring the pill: Praise and criticism in written feedback. Journal of Second Language Writing 10.3, 185-212.

Hyland, K. (1993). ESL computer writers: What can we do to help? System 21.1, 21-30.

Hyland, K. (2003). Second language writing. New York: Cambridge University Press.

Hyland K. \& F. Hyland. (eds.) (2006a). Feedback in second language writing: Contexts and issues. New York: Cambridge University Press.

Hyland, K. \& F. Hyland (2006b). Interpersonal aspects of response: Constructing and interpreting teacher written feedback. In K. Hyland \& F. Hyland (eds.), 206-224.

Jacobs, G., A. Curtis, G. Braine \& S. Huang (1998). Feedback on student writing: Taking the middle path. Journal of Second Language Writing 7.3, 307-317.

James, C. (1998). Errors in language learning and use: Exploring error analysis. London: Longman.

Johns, A. (1995). Teaching classroom and authentic genres: Initiating students into academic cultures and discourses. In Belcher \& Braine, (eds.), 277-291.

Johns, A. (2006). Student self-evaluation and reflection: The I-Search paper. In K. Hyland \& F. Hyland (eds.), 162-181.

Joyce, B. \& M. Weil (2000). Models of teaching. New Jersey, NJ: Prentice-Hall.

Kahmi-Stein, L. (2000). Looking to the future of TESOL teacher education: Web-based bulletin board discussions in a methods course. TESOL Quarterly 34.3, 423-455.

Kepner, C. (1991). An experiment in the relationship of types of written feedback to the development of writing skills. Modern Language Journal 75.3, 305-313.

Kern, R. \& M. Warschauer (2000). Introduction. In M. Warschauer \& R. Kern (eds.), Network-based language teaching: Concepts and practice. Cambridge: Cambridge University Press, 1-19.

Knoblauch, C. \& L. Brannon (1981). Teacher commentary on student writing: The state of the art. Freshman English News 18.2, 1-4.

Knoblauch, C. \& L. Brannon (1984). Rhetorical traditions and the teaching of writing. Upper Montclair, NJ: Boynton/Cook.

Krishnamurthy, S. (2005). A demonstration of the futility of using Microsoft Word's spelling and grammar check. <http://faculty.washington.edu/sandeep/check/> checked 26 December 2005.

Kroll, B. (ed.) (1990). Second language writing: Research insights for the classroom. Cambridge: Cambridge University Press.

Lalande, J. (1982). Reducing composition errors: An experiment. Modern Language Journal 66.2, 140-149.

Lamy, M-N. \& R. Goodfellow (1999). 'Reflective conversation' in the virtual language classroom. Language Learning and Technology 2.2, 43-61.

Lave, J. \& E. Wenger (1991). Situated learning: Legitimate peripheral participation. Cambridge: Cambridge University Press.

Lee, I. (2004). Error correction in L2 secondary writing classrooms: The case of Hong Kong. Journal of Second Language Writing 13.4, 285-312.

Leki, I. (1990). Coaching from the margins: issues in written response. In Kroll (ed.), 57-68.

Leki, I. (1991). The preferences of ESL students for error correction in college level writing classes. Foreign Language Annals 24.3, 203-218.
Leki, I. (2006). 'You cannot ignore': Graduate L2 students' experience of and responses to written feedback practices within their disciplines. In K. Hyland \& F. Hyland (eds.), 266-285.

Lim, W. \& G. Jacobs (2001). An analysis of students' dyadic interaction on a Dictogloss Task (ERIC Document Reproduction Service No. ED 456 649).

Lindblom-Ylanne, S. \& H. Pihlajamaki (2003). Can a collaborative network environment enhance essay-writing processes? British Journal of Educational Technology 34.1, 1730.

Liou, H-C. (1994). Practical considerations for multimedia courseware development: An EFL IVD experience. CALICO Journal, 11.3, 47-74.

Liu, J. (1997). A comparative study of ESL students' pre-/ post-conceptualisations of peer review in L2 composition. Paper presented at the 31st annual TESOL convention, 11-15 March, Orlando, FL.

Liu, J. \& J. Hansen (2002). Peer response in second language writing classrooms. Ann Arbor, MI: The University of Michigan Press.

Liu, J. \& R. Sadler (2003). The effect and affect of peer review in electronic versus traditional modes on L2 writing. Journal of English for Academic Purposes 2.3, 193227.

Liu, M., Z. Moore, L. Graham \& S. Lee (2002). A look at the research on computer-based technology use in second language learning: A review of the literature from 19902000. Journal of Research on Technology in Education 34.3, 250-274.

Lockhart, C. \& P. Ng (1993). How useful is peer response? Perspectives 5.1, 17-29.

Lockhart, C. \& P. Ng (1995). Analysing talk in peer response groups: Stances, functions and content. Language Learning 45.4, 605-625.

Long, M. (1996). The role of the linguistic environment in second language acquisition. In R. Ritchie \& T. Bhatia (eds.), Handbook of second language acquisition. San Diego, CA: Edward Arnold, 413-468.

Long, M. \& P. Porter (1985). Group work, interlanguage talk, and second language acquisition. TESOL Quarterly 19.2, 305-325.

Macrorie, K. (1980). Searching writing. Rochelle Par, NJ: Hayden Book Company.

Mangelsdorf, K. \& A. Schlumberger (1992). ESL student response stances in a peer review task. Journal of Second Language Writing 1.3, 235-254.

Master, P. (1995). Consciousness raising and article pedagogy. In Belcher \& Braine, (eds.), 183-205.

McGroarty, M. \& W. Zhu (1997). Triangulation in classroom research: A study of peer revision. Language Learning 47.1, $1-43$.

Meagher, M. \& F. Castaños (1996). Perceptions of American culture: The impact of an electronically-mediated cultural exchange program on Mexican high school students. In Herring (ed.), 187-202.

Mendoca, C. \& K. Johnson (1994). Peer review negotiations: Revision activities in ESL writing instruction. TESOL Quarterly 28.4, 745-768.

Milton, J. (1999). Lexical thickets and electronic gateways: Making text accessible by novice writers. In C. Candlin \& K. Hyland (eds.), Writing: Texts, processes and practices. London: Longman, 221-243.

Milton, J. (2004). From parrots to puppet masters: Fostering creative and authentic language use with online tools. In B. Holmberg, M. Shelly \& C. White (eds.), Distance education and language: Evolution and change. Clevedon: Multilingual Matters, 242-257.

Milton, J. (2006). Resource-rich web-based feedback: Helping learners become independent writers. In K. Hyland \& F. Hyland (eds.), 123-139. 
Min, H. T. (2005). Training students to become successful peer reviewers. System 33.2, 293-308.

Mitchell, R. \& F. Myles (2004). Second language learning theories. London: Arnold.

Mittan, R. (1989). The peer review process: Harnessing students' communicative power. In D. Johnson \& D. Roen (eds.), Richness in writing: Empowering ESL students. Longman: New York, 207-219.

Murphy, S. (2000). A sociocultural perspective on teacher response: Is there a student in the room? Assessing Writing 7.1, 79-90.

Nelson, G. (1997). How cultural differences affect written and oral communication: The case of peer response groups. In D. Sigsbee, B. Speck \& B. Maylath (eds.), Approaches to teaching non-native English speakers across the curriculum. San Francisco, CA: Jossey-Bass, 77-84.

Nelson, G. \& J. Carson (1995). Social dimensions of secondlanguage writing instruction: Peer response groups as cultural context. In D. Rubin (ed.), Composing social identity in written communication. Hillsdale, NJ: Lawrence Erlbaum, 89-109.

Nelson, G. \& J. Carson (1998). ESL students' perceptions of effectiveness in peer response groups. Journal of Second Language Writing 7.1, 113-131.

Nelson, G. \& J. Carson. (2006). Cultural issues in peer response: Revisiting 'culture'. In K. Hyland \& F. Hyland (eds.), 42-59.

Nelson, G. \& J. Murphy (1992). An L2 writing group: Task and social dimensions. Journal of Second Language Writing 1.3, 171-193.

Nelson, G. \& J. Murphy (1993). Peer response groups: Do L2 writers use peer comments in revising their drafts? TESOL Quarterly 27.1, 135-141.

O'Dowd, R. (2003). Understanding the 'other side': Intercultural learning in a Spanish-English e-mail exchange. Language Learning \& Technology 7.2, 118-144.

Ohta, A. (1995). Applying sociocultural theory to an analysis of learner discourse: Learner-learner collaborative interaction in the zone of proximal development. Issues in Applied Linguistics 6.2, 93-121.

Ohta, A. (2001). Second language acquisition processes in the classroom: Learning Japanese. Mahwah, NJ: Lawrence Erlbaum.

Palmquist, M. (1993). Network-supported interaction in two writing classrooms. Computers and Composition 10.4, 2557.

Patthey-Chavez, G. \& D. Ferris (1997). Writing conferences and the weaving of multi-voiced texts in college composition. Research in the Teaching of English 31.1, 5190.

Paulus, T. (1999). The effect of peer and teacher feedback on student writing. Journal of Second Language Writing 8.3, 265-289.

Peck, W. (1990). The effects of prompts on revision: A glimpse of the gap between planning and performance. In L. Flower, V. Stein, J. Ackerman, M. Kantz, K. Mc Cormick \& W. Peck. (eds.), Reading to write: Exploring a cognitive and social process. New York: Oxford University Press, 156-169.

Phinney, M. \& S. Khouri (1993). Computers, revision, and ESL writers: The role of experience. Journal of Second Language Writing 2.3, 257-277.

Plass, J. \& D. Chun (1996). A hypermedia system for CALL in a networked environment. In M. Warschauer (ed.), Telecollaboration in foreign language learning. Honolulu, HI: University of Hawai'i Press, 83-103.

Polio, C. (1997). Measures of linguistic accuracy in second language writing research. Language Learning, 47.1, 101143

Polio, C., C. Fleck \& N. Leder (1998). 'If I only had more time': ESL learners' changes in linguistic accuracy on essay revisions. Journal of Second Language Writing 7.1, 4368.

Powers, J. (1993). Rethinking writing center conferencing strategies for the ESL writer. Writing Center Journal 13, $39-47$.

Powers, J. \& J. Nelson (1995). L2 writers and the writing center: A national survey of writing centre conferencing at graduate institutions. Journal of Second Language Writing 4.2, 113-138.

Prior, P. (1995). Redefining the task: An ethnographic examination of writing and response in graduate seminars. In Belcher \& Braine, (eds.), 47-82.

Prior, P. (1998). Writing/disciplinarity: A sociohistoric account of literate activity in the academy. Mahwah, NJ: Lawrence Erlbaum.

Probst, R. E. (1989). Transactional theory and response to student writing. In C. Anson (ed.), Writing and response. Urbana, IL: NCTE, 68-79.

Radecki, P. \& J. Swales (1988). ESL student reaction to written comments on their work. System 16.3, 355-365.

Reid, J. (1994). Responding to ESL students' texts: The myths of appropriation. TESOL Quarterly 28.2, 273-294.

Riazi, A. (1997). Acquiring disciplinary literacy: A sociocognitive analysis of text production and learning among Iranian graduate students of education. Journal of Second Language Writing 6.2, 105-137.

Robb, T., S. Ross \& I. Shortreed (1986). Salience of feedback on error and its effect on EFL writing quality. TESOL Quarterly 20.1, 83-93.

Saito, H. (1994). Teachers' practices and students' preferences for feedback on second language writing: A case study of adult ESL learners. TESL Canada Journal 11.2, 46-70.

Schultz, J. (2000). Computers and collaborative writing in the foreign language curriculum. In M. Warschauer \& R. Kern (eds.), Network-based language learning: Concepts and practice. Cambridge: Cambridge University Press, 121-150.

Sengupta, S. (1998). Peer evaluation: 'I am not the teacher'. ELT Journal, 52.1, 19-28.

Sengupta, S. (2001). Exchanging ideas with peers in networkbased classrooms: An aid or a pain? Language Learning and Technology 5.1, 103-134.

Sheppard, K. (1992). Two feedback types: Do they make a difference? RELC Journal 23.1, 103-110.

Shermis, M. \& J. Burstein (eds.) (2003). Automated essay scoring: A cross-disciplinary perspective. Hillsdale, NJ: Lawrence Erlbaum.

Song, B. \& B. August (2002). Using portfolios to assess the writing of ESL students: A powerful alternative? Journal of Second Language Writing 11.1, 49-72.

Stanley, J. (1992). Coaching student writers to be effective peer evaluators. Journal of Second Language Writing 1.3, 217 233

Stoddard, B. \& C. MacArthur (1993). A peer editor strategy: Guiding learning disabled students in response and revision. Research in the Teaching of English 27.1, 76-103.

Sullivan, N. \& E. Pratt (1996). A comparative study of two ESL writing environments: A computer assisted classroom and a traditional oral classroom. System 24.4, 491-501.

Swaffar J., S. Romano, K. Arens \& P. Markley (eds.) (1998). Language learning on line: Research and pedagogy in the ESL and L2 computer classroom. Austin, TX: Labyrinth.

Tardy, C. (2006). Appropriation, Ownership, and Agency: Negotiating teacher feedback in academic settings. In $\mathrm{K}$. Hyland \& F. Hyland (eds.), 60-78.

Tella, S. (1992). Talking shop via email: A thematic and linguistic analysis of electronic mail communication (Research Report 99). Helsinki: Department of Teacher Education, University of Helsinki.

Thonus, T. (1999). How to communicate politely and be a tutor too: NS-NSS interaction and writing center practice. Text 19, 253-279. 
Thonus, T. (2001). Triangulation in the writing center: Tutor, tutee and instructor perceptions of the tutor's role. Writing Center Journal 22, 59-81.

Thonus, T. (2003). Tutor and student assessments of academic writing tutorials: What is success? Assessing Writing 8.2, 110-134.

Thonus, T. (2004). What are the differences? Tutor interactions with first- and second-language writers. Journal of Second Language Writing 13.3, 227-242.

Todd, R. (2001). Induction from self-selected concordances and self-correction. System 29.1, 91-102.

Truscott, J. (1996). The case against grammar correction in L2 writing classes. Language Learning 46.2, 327-369.

Truscott, J. (1999). The case for 'the case against grammar correction in L2 writing classes': A response to Ferris. Journal of Second Language Writing 8.2, 111-122.

Truscott, J. (2004). Evidence and conjecture on the effects of correction: A response to Chandler. Journal of Second Language Writing 13.4, 337-343.

Tsui, A. \& M. Ng (2000). Do secondary L2 writers benefit from peer comments? Journal of Second Language Writing 9.2, $147-170$.

Tuzi, F. (2004). The impact of e-feedback on the revisions of L2 writers in an academic writing course. Computers and Composition 21.2, 217-235.

Valenti, S., F. Neri \& A. Cucchiarelli (2003). An overview of current research on Automated Essay Grading. Journal of Information Technology Education 2, 319330.

van der Geest, T. \& T. Remmers (1994). The computer as means of communication for peer-review groups. Computers and Composition 11.3, 237-250.

Villamil, O. \& M. de Guerrero (1996). Peer revision in the L2 classroom: Social-cognitive activities, mediating strategies, and aspects of social behaviour. Journal of Second Language Writing 5.1, 51-75.

Villamil, O. \& M. de Guerrero (2006). Sociocultural theory: A framework for understanding socio-cognitive dimensions of peer feedback. In K. Hyland \& F. Hyland (eds.), 23-41.

Vygotsky, L. (1978). Mind in society: The development of higher psychological processes. Cambridge, MA: Harvard University Press.

Warden, C. \& J. Chen (1995). Improving feedback while decreasing teacher burden in R.O.C.: ESL business English writing classes, In P. Bruthiaux, T. Boswood \& B. Du-Babcock (eds.), Explorations in English for professional communications. Hong Kong: City University of Hong Kong, 125-137.
Ware, P. (2004). Confidence and competition online: ESL student perspectives on web-based discussions in the classroom. Computers and Composition 21.4, 451-468.

Ware, P. \& M. Warshauer (2006). Electronic feedback. In K. Hyland \& F. Hyland (eds.), 105-122.

Warschauer, M. (1997). Computer-mediated collaborative learning: Theory and practice. Modern Language Journal 81.4, 470-481.

Warschauer, M. (1999). Electronic literacies: Language, culture, and power in online education. Mahwah, NJ: Lawrence Erlbaum.

Warschauer, M. (2002). Networking into academic discourse. Journal of English for Academic Purposes 1.1, 45-58.

Warschauer, M., L. Turbee \& B. Roberts (1996). Computer learning networks and student empowerment. System 24.1, $1-14$.

Weigle, S. \& G. Nelson (2004). Novice tutors and their ESL tutees: Three case studies of tutor roles and perceptions of tutorial success. Journal of Second Language Writing 13.3, 203-225.

Weissberg, R. (2006). Conversations about writing: Building oral scaffolds with advanced L2 writers. In K. Hyland \& F. Hyland (eds.), 246-264.

Williams, J. (2002). Undergraduate second language writers in the writing center. Journal of Basic Writing 21.2, 73-91.

Williams, J. (2004). Tutoring and revision: Second language writers in the writing center. Journal of Second Language Writing 13.3, 173-201.

Williams, J. \& C. Severino (2004). The writing center and second language writers. Journal of Second Language Writing 13.3, 165-172.

Yates, R. \& J. Kenkel (2002). Responding to sentence level errors in writing. Journal of Second Language Writing 11.1, 29-47.

Yuan, Y. (2003). The use of chat rooms in an ESL setting. Computers and Composition 20.2, 194-206.

Zamel, V. (1985). Responding to student writing. TESOL Quarterly 19.1, 79-101.

Zhang, S. (1995). Re-examining the affective advantages of peer feedback in the ESL writing class. Journal of Second Language Writing 4.3, 209-222.

Zhu, W. (1995). Effects of training for peer response on students' comments and interaction. Written Communication 12.4, 492-528.

Zhu, W. (2004). Faculty views on the importance of writing, the nature of academic writing, and the teaching and responding to writing in the disciplines. Journal of Second Language Writing 13.1, 29-48. 